김홍석 ${ }^{a *}$

\title{
Prediction of Cutting Forces and Estimation of Size Effects in End Milling Operations by Determining Instantaneous Cutting Force Constants
}

\author{
Hong Seok Kim ${ }^{\mathrm{a}^{*}}$ \\ ${ }^{a}$ Department of Mechanical and Automotive Engineering, Seoul National University of Science and Technology, \\ 232 Gongneung-ro, Nowon-gu, Seoul, 139-743, Republic of Korea
}

\begin{tabular}{|c|c|c|c|}
\hline \multicolumn{4}{|c|}{ ARTICLE INFO } \\
\hline \multicolumn{4}{|c|}{ Article history: } \\
\hline Received & 25 & July & 2013 \\
\hline Revised & 1 & October & 2013 \\
\hline Accepted & 16 & October & 2013 \\
\hline
\end{tabular}

Keywords:

End milling

Cutting force

Size effect

Instantaneous cutting force constants

\begin{abstract}
This paper presents a simple procedure to obtain the instantaneous cutting force constants needed to predict milling forces. Cutting force data measured in a series of slot milling tests were used to determine the cutting force constants at different feed rates. The values of the cutting force constants were determined directly at the tool rotation angle that maximized the uncut chip thickness. Then, the instantaneous cutting force constant was obtained as a function of the instantaneous uncut chip thickness. This approach can greatly enhance the accuracy of the mechanistic cutting force model for end milling. In addition, the influences of several cutting parameters on the cutting forces, such as the tool helix angle and axial depth of cut, were discussed.
\end{abstract}

\section{1. 서 론}

밀링 공정은 자동차, 항공, 의료, 전자 등 여러 산업분야에서 다 양한 형상의 부품을 정밀하게 가동하는데 널리 활용되고 있다. 밀 링 공정에서 절삭력(Cutting force)은 가공조건의 결정, 공구수명, 제품의 품질 및 생산성 등에 영향을 미치는 가장 중요한 인자로 정확한 절삭력 모델의 수립을 위하여 많은 연구가 진행되어 왔다. 절삭력은 가공물의 기계적 성질, 마찰(Friction), 공구(Tool), 가공 시스템의 강성(Rigidity) 등 매우 다양한 인자에 영향을 받기 때문 에 그 복잡한 메카니즘을 모두 이론적으로 설명하기는 힘들다. 따 라서 절삭력이 절삭단면적과 비례한다는 가정 하에 절삭력 계수 (Cutting force constants)를 다양한 공정변수와 관련시키는 연구
가 많이 진행되고 있다.

Armarego 등 ${ }^{[1]}$ 과 Budak 등 ${ }^{[2]}$ 은 경사절삭(Oblique cutting) 이 론에 근거하여 전단각(Shear angle), 마찰각(Frcition angle), 전단 항복강도(Shear yield strength) 등에 따라 변화하는 절삭력 계수 를 예측하였고, Yucesan 등 ${ }^{[3]}$ 은 공구경사면의 마찰과 압력 분포, 칩 유동 각(Chip flow angle) 등이 미치는 영향을 추가적으로 고 려하였다. $\mathrm{Kang}^{[4]}$ 등은 절삭날의 공구반경을 고려하여 마이크로 밀링에서 절삭력을 예측하고자 하였다. 하지만 이러한 방법은 많은 절삭 실험을 통해 다양한 변수들의 값을 직접 측정해야 하는 단점 이 있기 때문에 절삭 실험으로부터 직접 절삭력 계수를 측정하는 연구도 많이 진행되고 있다. Kline 등[5]은 일정한 값의 절삭력 계 수를 이용하여 엔드 밀링의 절삭력을 예측하였고, Sutherland 등[6]

* Corresponding author. Tel.: +82-2-970-6333

$$
\text { Fax: +82-2-949-1458 }
$$

E-mail address: hongseok@seoultech.ac.kr (Hong Seok Kim). 
과 Afazov 등[7]은 공구의 변형과 럿아웃(runout)을 고려하여 절삭 력 계수를 결정하였다. 또한 Altintas 등[8]과 Perez 등이은 절삭력 계수를 평균 미변형 칩두께에 대한 함수로 나타내어 절살력 예측의 정확성을 향상시키고자 하였다. 하지만 이러한 방법도 대부분 평균 칩두께나 절삭력으로부터 계수를 결정하기 때문에 공구 회전 시 변화하는 절삭력을 정확히 반영하기 힘들다.

밀링 공정은 공구의 회전각에 따라 절삭 단면이 연속적으로 변화 하기 때문에 절삭력이 절삭 메카니즘 뿐 아니라 경작력(Ploughing force), 럿아웃 등 다양한 인자에 영향을 받게 된다. 따라서 공구 회전에 따라 변화하는 순간 절삭력 계수의 결정이 필요하며 본 연 구에서는 이를 위한 간단한 측정 방법을 제시하고자 하였다. 슬롯 밀링(Slot milling)에서 평균 미변형 칩두께가 최대가 되는 지점의 절삭력 데이타는 반경방향과 접선방향 절삭력 값과 거의 일치하기 때문에 절삭력 계수를 직접 측정할 수 있다. 따라서 서로 다른 날당 이송량(Feed per tooth) 조건에서 측정된 절삭력 값으로부터 순간 절삭력 계수를 미변형 칩두께에 대한 함수로 나타내었고, 이를 통 해 엔드 밀링의 절삭력을 예측하였다. 실험과 예측 결과의 비교를 통해 순간 절삭력 계수를 적용한 절삭력 모델의 정확성을 검증할 수 있었다. 또한 절삭날의 비틀림 각(Helix angle)이나 절입깊이 (Axial depth of cut)와 같은 공정 변수가 엔드 밀링의 절삭력 변화 에 미치는 영향을 고찰하였다.

\section{2. 본 론}

\section{1 절삭력 모델}

Tlusty 등 ${ }^{[10]}$ 의 절삭력 모델에 따르면 절삭력은 절삭단면적에 비 례하며, 엔드 밀링의 반경방향 및 접선방향 미소 절삭력 $d F_{t}$ 와 $d F_{r}$ 은 다음과 같이 가정할 수 있다.

$$
\begin{aligned}
& d F_{t}(\theta)=K_{t} h(\theta) d z \\
& d F_{r}(\theta)=K_{r} h(\theta) d z
\end{aligned}
$$

여기서 $K_{t}$ 와 $K_{r}$ 은 각각 접선방향과 반경방향의 절삭력 계수이 고 $h$ 는 미변형 칩두께의 크기를 나타내며, $d z$ 와 $\theta$ 는 각각 엔드밀 날의 미소 깊이와 위상각을 나타낸다. Fig. 1 에 따라 엔드 밀링 공 정에서 이송방향과 수직방향의 미소 힘 $d F_{x}$ 와 $d F_{y}$ 는 다음과 같이 변환하여 나타낼 수 있다.

$$
\left[\begin{array}{l}
d F_{x}(\theta) \\
d F_{y}(\theta)
\end{array}\right]=\left[\begin{array}{c}
-\cos \theta-\sin \theta \\
\sin \theta-\cos \theta
\end{array}\right]\left[\begin{array}{l}
d F_{t}(\theta) \\
d F_{r}(\theta)
\end{array}\right]
$$

범용 엔드 밀링에서 $h(\theta)$ 와 $d z$ 는 Fig. 1을 참고하여 다음의 식 으로 나타낼 수 있다.

$$
\begin{aligned}
& h(\theta)=f_{t} \sin \theta \\
& d z=\frac{D}{2 \tan \beta} d \theta
\end{aligned}
$$

여기서 $D$ 는 공구의 직경, $f_{t}$ 는 날당 이송량, $\beta$ 는 엔드밀 날의 비틀림 각이다. 식 (1), (2), (4), (5)를 이용하면 식 (3)을 다음과 같이 나타낼 수 있다.

$$
\left[\begin{array}{l}
d F_{x}(\theta) \\
d F_{y}(\theta)
\end{array}\right]=\frac{f_{t} D \sin \theta}{2 \tan \beta}\left[\begin{array}{c}
-\cos \theta-\sin \theta \\
\sin \theta-\cos \theta
\end{array}\right]\left[\begin{array}{l}
k_{t} d \theta \\
k_{r} d \theta
\end{array}\right]
$$

식 (6)을 공구가 물리는 시작 각 $\theta_{s}$ 과 끝 각 $\theta_{e}$ 사이에서 적분하 면 임의의 위상각에 대한 $\mathrm{x}$ 및 $\mathrm{y}$ 방향 절삭력을 다음과 같이 계산 할 수 있다.

$$
F_{x}(\theta)=\int_{\theta_{s}}^{\theta_{e}} \frac{f_{t} D}{4 \tan \beta}\left[-K_{t} \sin 2 \theta+K_{r}(\cos 2 \theta-1)\right] d \theta
$$

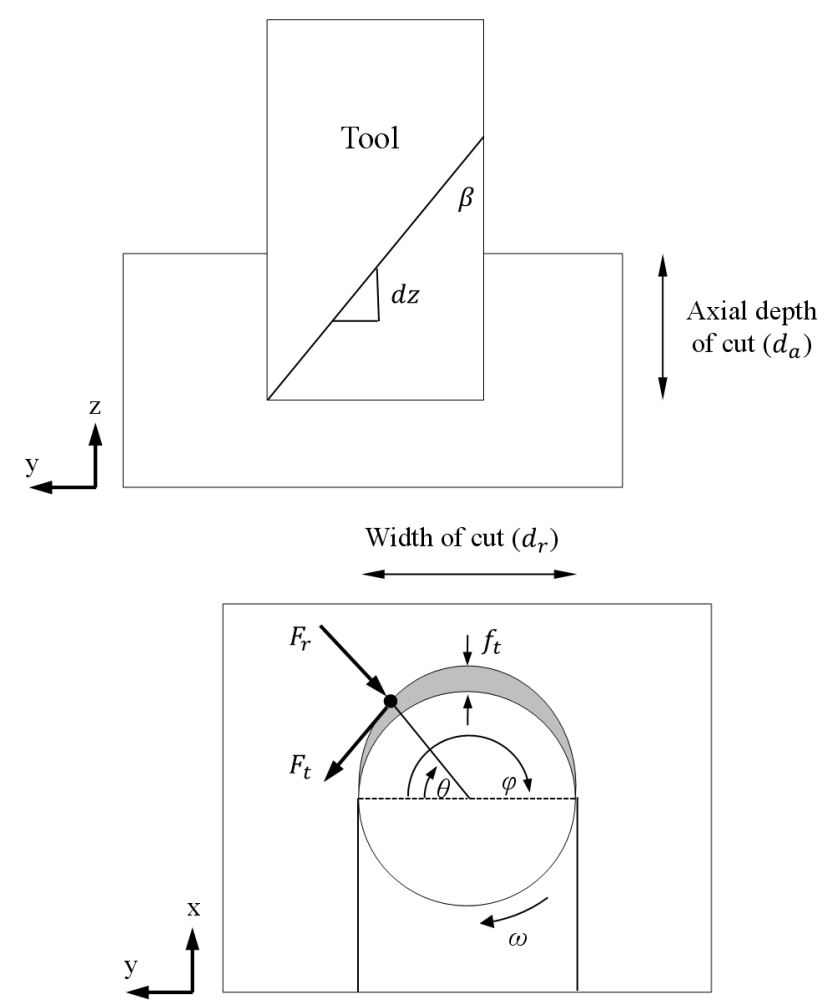

Fig. 1 Schematic illustration of helical slot milling operation 

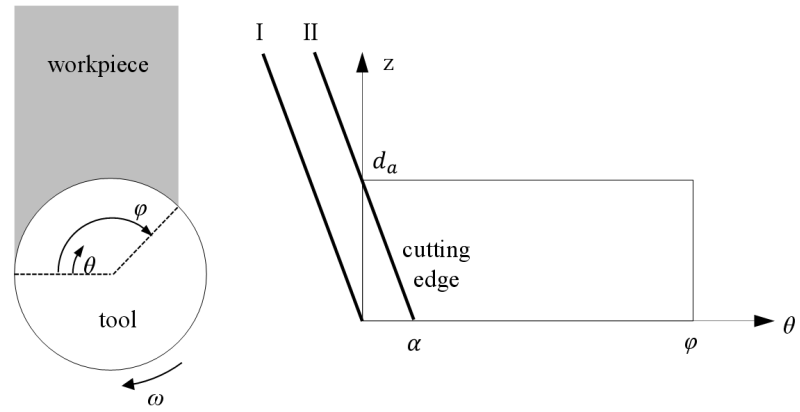

Fig. 2 Details of helical end milling operation

$$
F_{y}(\theta)=\int_{\theta_{s}}^{\theta_{e}} \frac{f_{t} D}{4 \tan \beta}\left[K_{t}(1-\cos 2 \theta)-K_{r} \sin 2 \theta\right] d \theta
$$

Fig. 2에 나타난 것처럼 엔드밀 날이 피삭재를 절삭하기 위해서 는 절삭각 $\phi$ 만큼의 공구회전이 필요하다. 엔드밀 날에 비틀림 각 이 존재하기 때문에 공구 회전시 절삭날이 가공물에 순차적으로 물리게 되고, 엔드밀 날이 물림깊이 $d_{a}$ 에 완전히 물리기 위해서는 Fig. 2에 서처럼 I에서 II 만큼의 회전이 필요하다. 이에 해당하는 물림각 $\alpha$ 는 다음과 같이 계산할 수 있다.

$$
\alpha=\frac{2 d_{a}}{D} \tan \beta
$$

물림각이 피삭재의 절삭각 $\phi$ 보다 작은 경우 ${ }^{[1]}$ 절삭력 계산을 위하여 다음과 같은 세 개의 적분 구간을 선정할 수 있다.

$$
\begin{aligned}
& {\left[\theta_{s}, \theta_{e}\right]=[0, \theta] \quad 0 \leq \theta<\alpha} \\
& {\left[\theta_{s}, \theta_{e}\right]=[\theta-\alpha, \theta] \quad \alpha \leq \theta<\phi} \\
& {\left[\theta_{s}, \theta_{e}\right]=[\theta-\alpha, \phi] \quad \phi \leq \theta<\phi+\alpha}
\end{aligned}
$$

본 연구는 슬롯밀링 공정을 대상으로 하였기 때문에 절삭각은 $180^{\circ}$ 이다. 엔드밀 날의 물림각의 존재하기 때문에 실제 날당 절삭 력의 측정구간은 절삭각보다 커지게 되며, 절삭날이 2 개 이상인 공 구의 경우에는 절삭날 입구와 출구영역에서 물림각에 의한 절삭력 을 중첩하여 나타내야 한다. 하지만 본 연구에서는 한 개의 절삭날 을 가지는 엔드 밀을 대상으로 하였기 때문에 이에 대한 고려는 제외하였다.

\section{2 순간 절삭력 계수의 결정}

엔드 밀링 공정에서 공구회전에 따라 변화하는 순간 절삭력 계수
Table 1 Experimental conditions for cutting force constants

\begin{tabular}{l|l}
\hline \hline Cutter & Carbide end-mill \\
\hline Cutter diameter & $19.06 \mathrm{~mm}$ \\
\hline Helix angle & $30 \mathrm{o}$ \\
\hline Radial depth of cut & $19.06 \mathrm{~mm}$ (slotting) \\
\hline Axial depth of cut & $7.62 \mathrm{~mm}$ \\
\hline Spindle rotation speed & $500 \mathrm{rpm}$ \\
\hline Feed per tooth & $12.7 \sim 50.8 \mu \mathrm{m} /$ tooth \\
\hline Workpiece & Titanium alloy \\
\hline
\end{tabular}

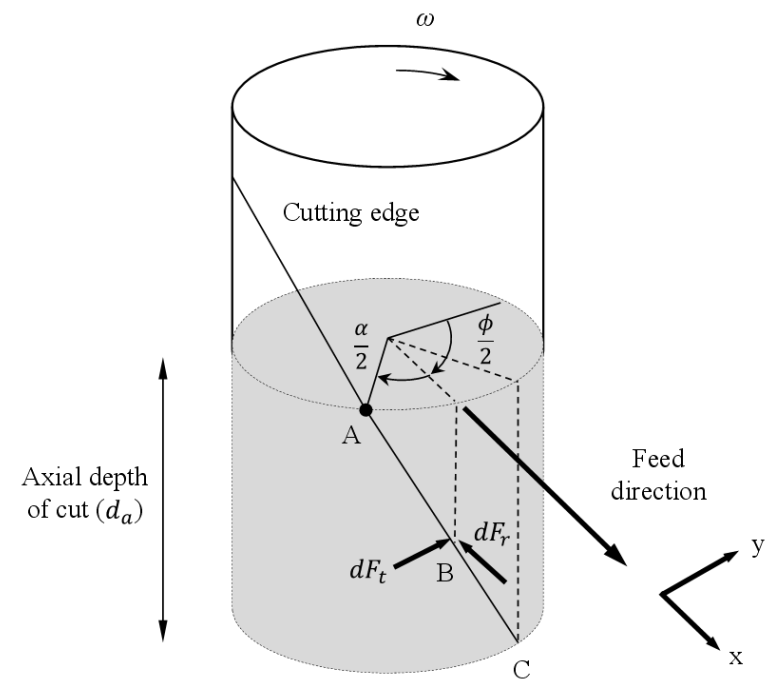

Fig. 3 Details of helical end milling tool

를 결정하기 위하여 Table 1 과 같은 조건에서 수행된 실험 결과 ${ }^{[12]}$ 를 활용하였다. 가공소재인 티타늄은 $6 \% \mathrm{Al}, 4 \%, \mathrm{~V}$ 합금이며 세 로탄성계수 $110 \mathrm{GPa}$, 푸아송 비 0.34 , 인장강도 $900 \mathrm{MPa}$ 의 물성 을 가진다.

Fig. 3에 나타낸 것처럼 본 연구에서의 절삭력 계수는 엔드밀 날의 위상각이 $\theta=\phi / 2+\alpha / 2$ 가 되는 지점에서 측정하였다. 이 지 점에서는 엔드밀 날 $\mathrm{AC}$ 가 피삭재에 물리게 되고 그 중간지점인 $\mathrm{B}$ 점에서의 반경방향 및 접선방향이 절삭력을 측정하는 $\mathrm{x}$ 및 $\mathrm{y}$ 방 향과 각각 일치하게 된다. B점 이외의 영역에서는 절삭력의 방향 이 변화하지만 $\mathrm{AC}$ 구간과 $\mathrm{BC}$ 구간의 대칭성으로 인하여 절삭력 성 분의 일부가 상쇄되기 때문에 $\mathrm{B}$ 점 기준 반경방향 및 접선방향 절 삭력 성분만이 최종적으로 존재하게 된다. 따라서 이 지점에서 측 정된 $\mathrm{x}$ 및 $\mathrm{y}$ 방향 절삭력은 절삭력 계산시 각각 반경방향 및 접선 방향 절삭력을 나타내는것으로 볼 수 있다. 또한 이 지점에서는 B 점에서의 미변형 칩두께가 엔드밀 날의 날당이송량과 같아지기 때 문에 측정된 $\mathrm{x}$ 및 $\mathrm{y}$ 방향 절삭력을 절삭단면적으로 나누면 현재 날당이송량에 대한 절삭력 계수 $K_{r}$ 및 $K_{t}$ 값을 구할 수 있다. 이와 같은 방법은 항상 동일한 위치의 엔드밀 날 위상각에서 절삭력을 
측정하여 계수를 결정하기 때문에 변화하는 위상각에서 측정한 데 이터를 아용하는 기존 방법과 비교할 때 절삭력 예측 성능을 향상 시킬 수 있을 것으로 판단된다.

Fig. 4은 서로 다른 날당 이송량 값에서 결정된 절삭력 계수를 이 용하여 $\mathrm{x}$ 및 $\mathrm{y}$ 방향 절삭력을 예측한 결과를 보여주고 있다. 이론 및 실험 결과로부터 날당 이송량이 증가할수록 절삭 단면적이 증가 하여 절삭력이 증가하는 것을 확인할 수 있다. 하지만 날당 이송량과 절삭력 계수는 서로 비례관계에 있지 않기 때문에 절삭력의 증가가 선형적이지는 않았다. 또한 엔드밀 날의 위상각이 $\theta=\phi / 2+\alpha / 2$ 인 점에서 측정한 일정한 값의 절삭력 계수를 사용하였기 때문에 실험 과 절삭력 모델의 예측 결과 사이에는 상당한 오차가 발생하였다. 절삭력 피크 부분의 크기와 위치에서도 오차를 확인할 수 있었으 며, 특히 미변형 칩두께가 날당이송량에 비해 작아지는 엔드밀 날 의 입구와 출구영역에서 오차가 커지는 것을 확인할 수 있었다.

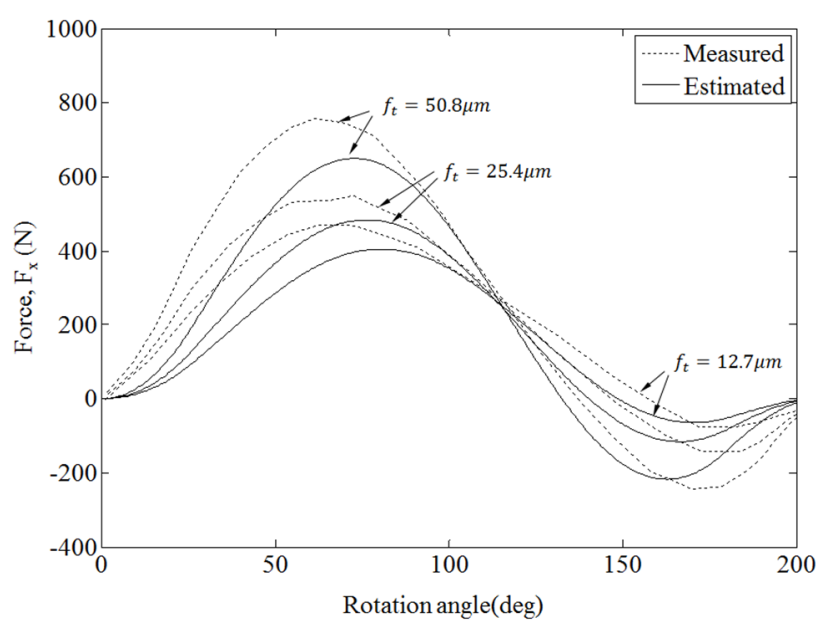

(a) $\mathrm{x}$-direction

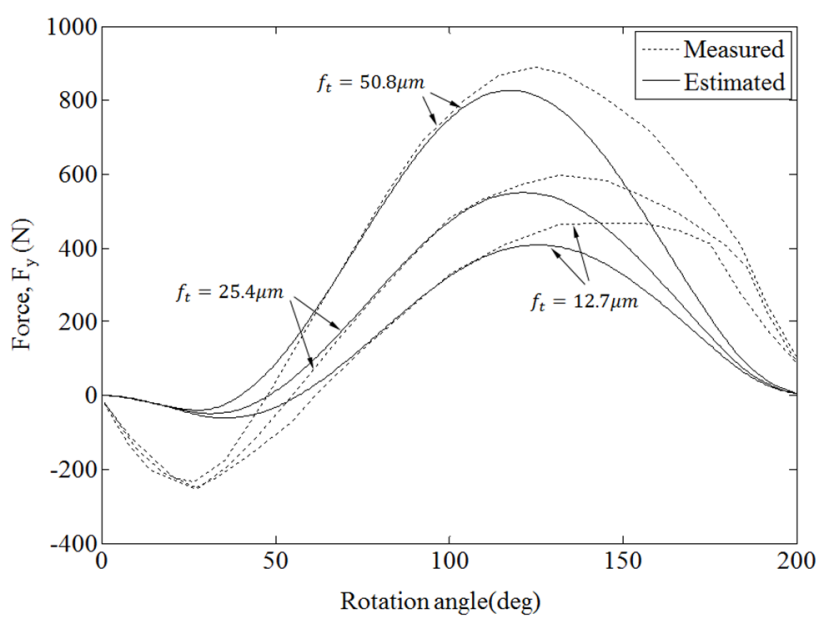

(b) y-direction

Fig. 4 Comparison of measured and predicted cutting forces at different feed rates and constant cutting force constants
엔드 밀링에서 $\mathrm{x}$ 및 $\mathrm{y}$ 방향 절삭력을 정확하게 예측하기 위한 순간 절삭력 계수를 구하기 위하여 서로 다른 날당이송량 조건에서 계산된 절삭력 계수를 Fig. 5에 회귀하여 나타내었다. 미변형칩두 께의 크기가 큰 영역에서는 절삭력 계수의 변화가 크지 않았으나 미변형칩두께가 $50 \mu \mathrm{m}$ 보다 작아지면서 절삭력 계수의 크기가 급 격히 증가하는 것을 확인할 수 있었다. 이러한 현상은 미변형 칩두 께의 크기가 공구선단 반경의 크기에 근접하면서 나타나는 크기효 과에서 그 주된 원인을 찾을 수 있다. 이러한 조건에서는 경작력의 상대적인 비율이 증가하여 비절삭에너지가 커지며 전단각, 경사각 등 절삭 파라미터가 변화되어 절삭 메커니즘에 변화를 일으키게 된다. 또한 미변형 칩두께가 작은 경우에는 런아웃 및 진동에 의한 절삭 단면적의 상대적인 변화가 커지기 때문에 럿아웃 및 진동이 절삭력의 크기 및 변화에 미치는 영향이 증가할 것으로 예상된다. 본 연구에서는 서로 다른 날당 이송량에서 측정된 절삭력 계수로부 터 절삭력의 크기효과를 정량적으로 표시하였으나 상기에 언급한 요소들에 대한 크기효가를 분리하여 모델링 하지는 않았다. 향후 보다 정확한 절삭 메커니즘의 분석을 위해서 이에 대한 추가 연구 가 필요하다.

Fig. 5에서 계산된 순간 절삭력 계수를 이용하여 반경방향 및 접선방향 절삭력을 예측한 결과를 Fig. 6에 나타내었다. 크기효과 를 고려한 경우 칩두께가 감소하는 엔드밀 날의 입구와 출구 영역 에서 순간 절삭력 계수의 증가에 따른 절삭력의 변화가 급격히 일 어남을 볼 수 있다. 크기효과를 고려하지 않은 경우는 크기효과를 고려한 경우와 비교할 때 절삭력 예측 값이 상당히 과소평가 되어 있음을 확인할 수 있는데, 특히 공구회전각이 $50^{\circ}$ 보다 작거나 $150^{\circ}$ 보다 큰 구간에서 최대 $300 \mathrm{~N}$ 의 절삭력 오차가 발생함을 알 수 있다.

이에 대한 보다 정량적인 분석을 위하여 미변형 칩두께에 따른

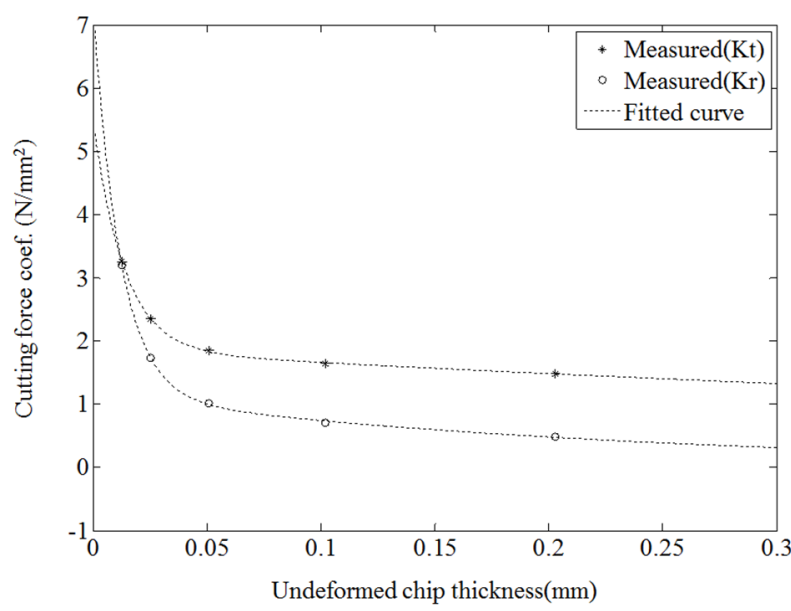

Fig. 5 Instantaneous cutting force constants at different undeformed chip thickness 


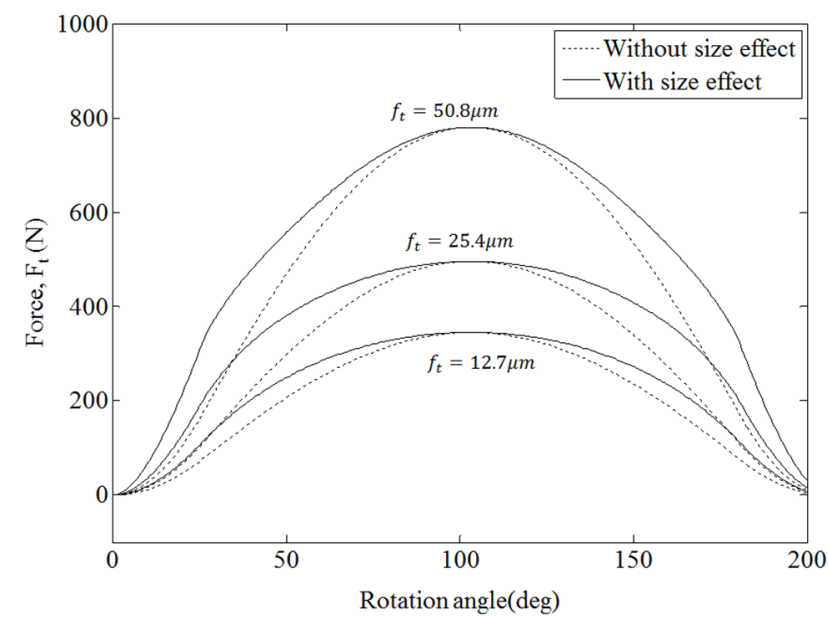

(a) tangential direction

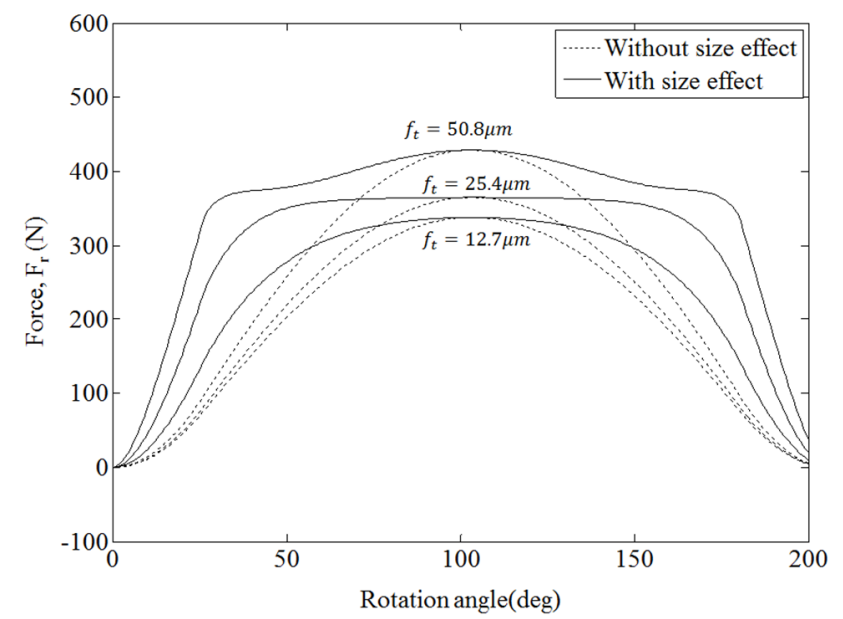

(b) radial direction

Fig. 6 Predicted cutting forces in tangential and radial directions with and without size effect

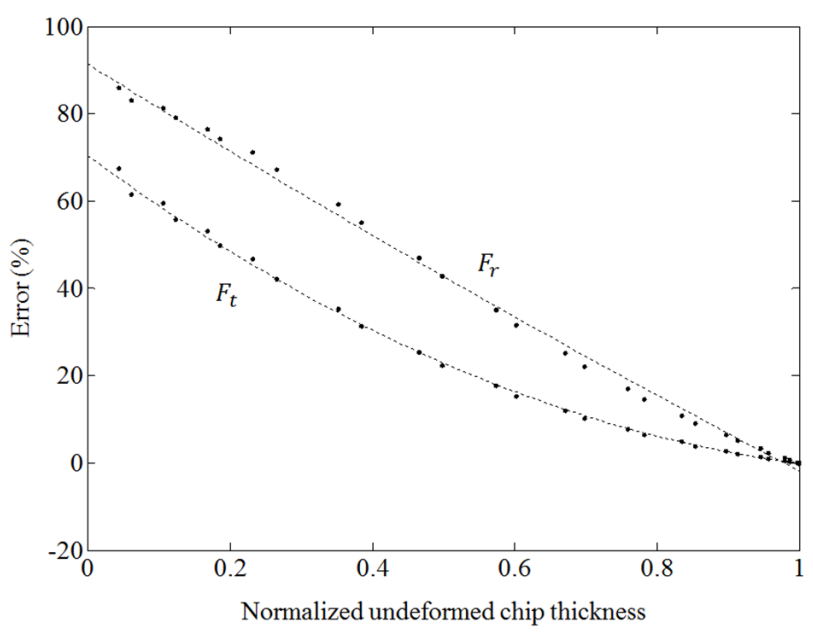

Fig. 7 Error in cutting forces vs. normalized undeformed chip thickness $\left(f_{t}=50.8 \mu \mathrm{m}\right)$
절삭력 계수의 변화를 보정하지 않은 경우에 발생하는 반경방향 및 접선방향 절삭력 오차를 Fig. 7에 나타내었다. 미변형 칩두께가 최대인 지점에서 계산한 절삭력 계수를 사용하였기 때문에 현재 미변형 칩두께를 최대 미변형 칩두께 값에 대하여 정규화 하여 표 시하였다. 따라서 정규화된 미변형 칩두께가 1 인 경우에는 오차가 없으며, 1 보다 작아질수록 크기효과에 의한 절삭력의 오차가 증가 하는 것을 확인할 수 있다.

공구회전시 변화하는 미변형 칩두께에 따른 순간 절삭력 계수를 보정하여 $\mathrm{x}$ 및 $\mathrm{y}$ 방향 절삭력을 예측한 결과를 Fig. 8에 나타내었 다. Fig. 4과 비교하였을 때 모든 날당이송량 조건에서 절삭력 모델 의 예측 성능이 크게 향상된 것을 볼 수 있었다. 특히 미변형칩두께 가 작아지는 절삭각 구간에서 측정값과 예측값 사이의 오차가 현저 히 감소하였으며, 절삭력 피크의 크기나 위치에서도 예측 성능이 향상된 것을 확인할 수 있었다. 하지만 오차의 크기는 날당이송량

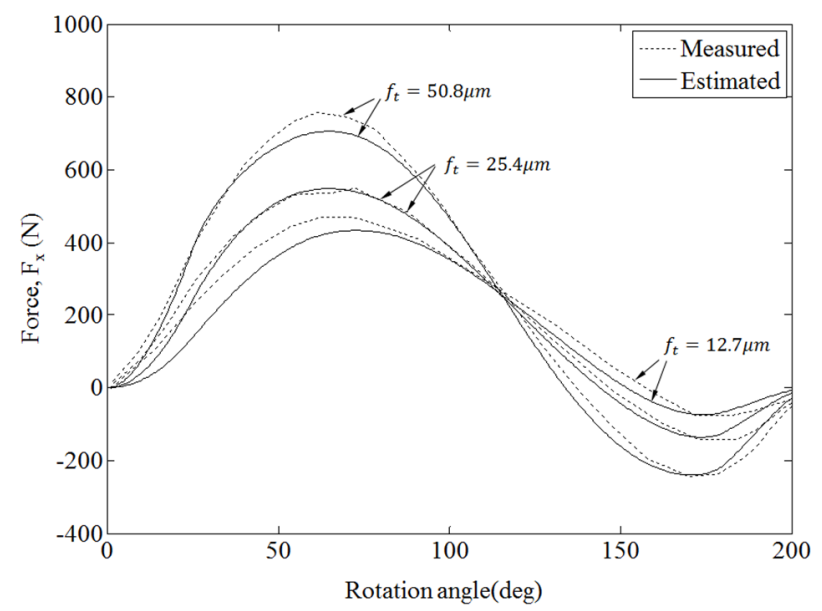

(a) $\mathrm{x}$-direction

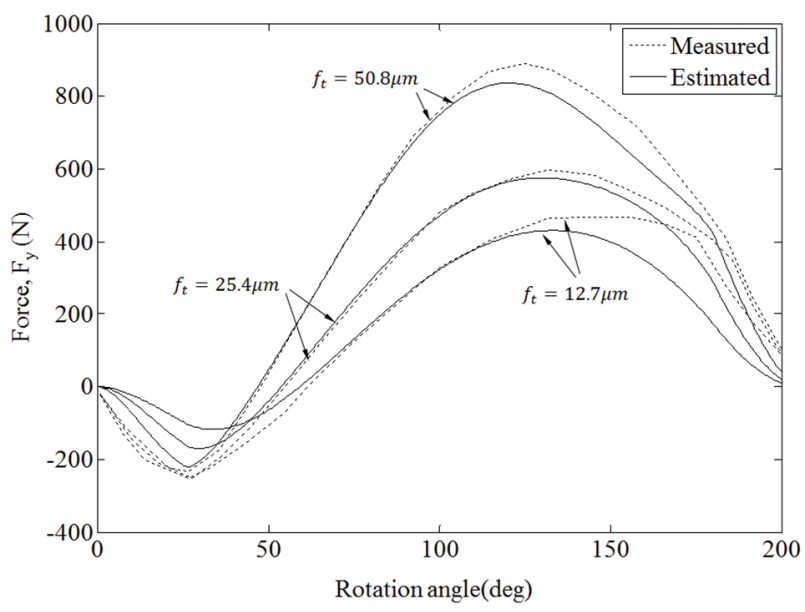

(a) y-direction

Fig. 8 Comparison of measured and predicted cutting forces with instantaneous cutting force constants at different feed rates 
이 작아질수록 증가하는 것이 관찰되었다. 본 연구에서의 순간 절 삭력 계수는 공구가 특정한 회전각을 가지는 지점에서 측정되어 미변형 칩두께에 대하여 회귀하여 나타낸 것으로, 실제 공구회전 시에는 미변형 칩두께의 크기가 같아도 럿아웃이나 진동 등이 미치 는 영향이 다를 것으로 예상된다. 이러한 조건에서는 절삭력 모델 의 오차가 증가할 것이며, 보다 정확한 절삭력의 예측과 절삭 메커 니즘의 분석을 위해서는 절삭력 계수의 보정만이 아닌 앞에서 언급 한 다양한 크기효과의 인자들에 대한 독립적인 모델링 연구가 필요 한 것으로 판단된다.

\section{3 절입깊이 및 비틀림 각의 영향}

본 절에서는 개선된 절삭력 모델을 이용하여 공구의 비틀림 각과 절입깊이와 같은 공정변수가 엔드밀링은 절삭력 특성에 미치는 영 향을 분석하였다.

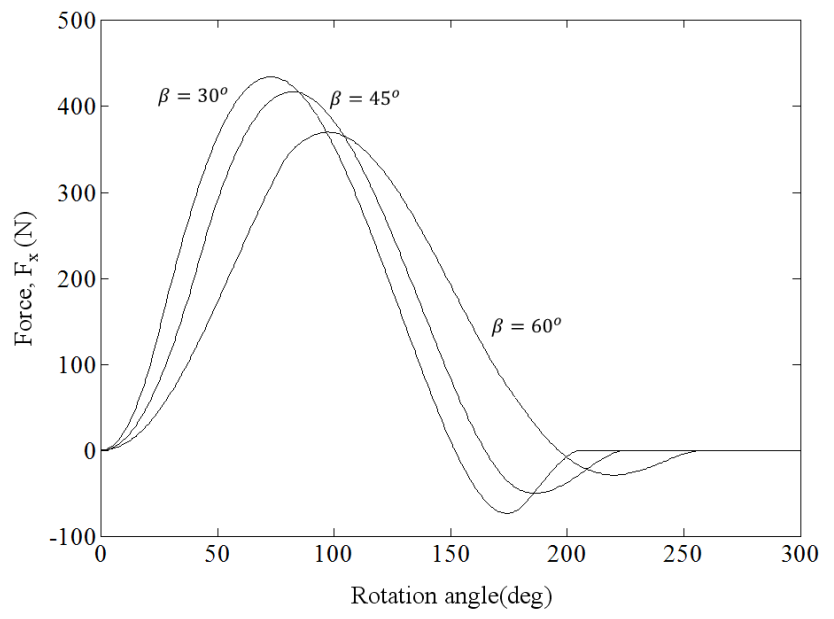

(a) $x$-direction

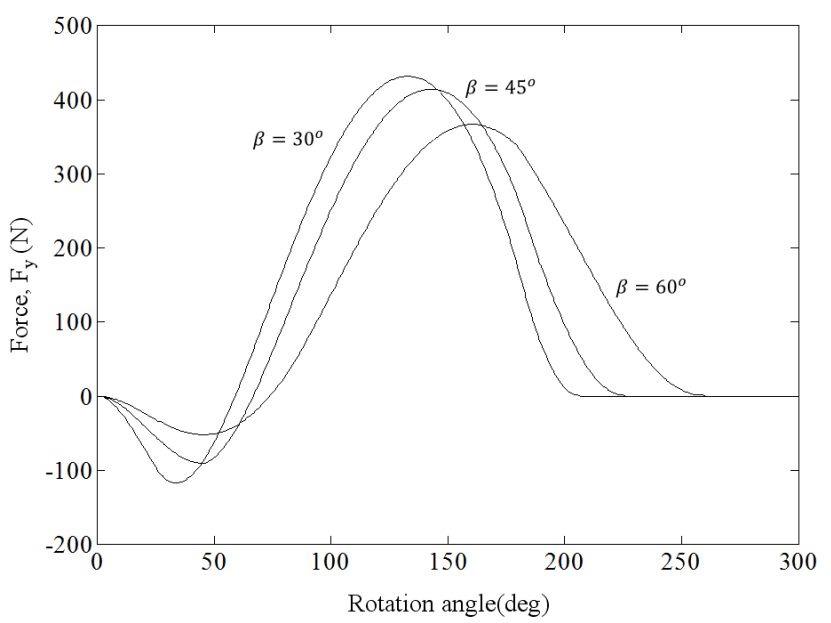

(b) y-direction

Fig. 9 Estimated cutting forces at different tool helix angles $\left(\mathbf{f}_{\mathrm{t}}=12.7 \mu \mathrm{m}\right)$
Fig. 9은 엔드밀 날의 비틀림 각 변화에 따른 절삭력의 변화를 보여주고 있다. 비틀림 각이 증가하면 엔드밀 날과 공작물의 물림 길이가 증가하면서 절삭력이 최대값이 다소 감소하는 것을 확인할 수 있었다. 하지만 물림길이가 증가하면 절삭력이 발생하는 공구날 의 회전각 범위도 증가하는 것을 볼 수 있다. 이러한 현상에 의하여 슬롯 밀링의 경우 절삭날의 개수가 두 개 이상이면 엔드밀 날의 입구와 출구 영역에서 절삭력이 중첩되어 나타나게 된다. 이러한 중첩 구간은 공구의 비틀림 각이 증가할수록 커지게 되면 전체 절 삭력 곡선의 형상에도 많은 영향을 미치게 된다.

Fig. 10 은 절입 깊이의 변화에 따른 절삭력의 변화를 보여주고 있다. 절입깊이는 본 연구에서 고려하는 절삭 메커니즘에 큰 영향 을 미치는 변수가 아니기 때문에 절삭력 곡선의 모양에는 큰 차이 가없었고 절삭력의 피크 값도 절입 깊이에 비례하는 것을 확인 할 수 있었다. 단 절입 깊이의 변화는 엔드밀 날의 비틀림 각이 일정한 경우에도 물림각의 변화를 발생시키기 때문에 공구날이 절삭작용 을 하는 회전각 범위에는 차이가 있었다.

본 연구에서는 엔드 밀링에서 나타나는 크기효과를 미변형 칩두 께에 대한 순간 절삭력 계수를 결정하여 설명하였기 때문에 절삭날 의 비틀림 각이나 절입깊이 등 공정변수들의 영향에 대한 절삭력 모델의 유효성은 검증하지 않았다. 향후 이러한 공정변수 뿐 아니 라 공구재료 및 가공물의 영향을 고려한 추가적인 실험을 실시할 계획이며 절삭력 모델의 정확성을 향상시킬 계획이다. 또한 요즘 많은 연구가 진행되고 있는 마이크로 밀링 가공의 절삭 메카니즘 분석에도 본 연구 결과의 활용이 가능할 것으로 판단된다. 절삭력 모델의 예측 값과 실험결과와의 비교를 통하여 마이크로 밀링에서 보다 현저해지는 럿아웃 및 공구변형의 영향에 대한 크기효과를 정량적으로 분석할 수 있을 것이다.

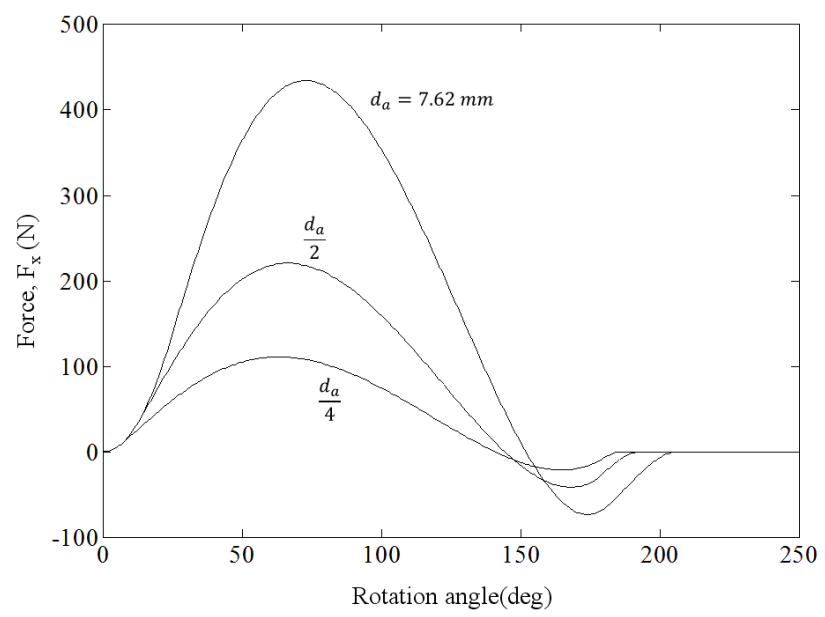

Fig. 10 Estimated cutting forces at different axial depth of cut $\left(\mathbf{f}_{\mathbf{t}}=12.7 \mu \mathrm{m}\right)$ 


\section{3. 결 론}

본 연구에서는 엔드 밀링 공정의 절삭 메커니즘을 이해하고 절삭 성능을 향상시키기 위한 절삭력 모델의 수립과 개선에 대한 연구를 진행하였다. 다양한 날당 이송량 조건에서 얻어진 절삭력 데이터로 부터 미변형 칩두께에 따른 순간 절삭력 계수를 계산하였고, 이를 밀링 공정에 적용하여 절삭력을 예측하였다. 제시된 순간 절삭력 측정 방법은 복잡한 계산이나 많은 실험을 필요치 않다는 측면에서 기존 방법들과 차별성이 있었으며, 모델의 정확성은 실험결과와의 비교를 통하여 확인할 수 있었다. 특히 미변형 칩두께가 감소하는 엔드밀 날의 입구와 출구 영역에서 절삭력 예측의 정확성을 현저히 향상시킬 수 있었다. 향후 가공물과 공구재료 및 다양한 공정변수 들의 영향을 고려하여 절삭력 모델의 성능을 향상시킬 계획이며, 마이크로 밀링을 위한 절삭 메카니즘 분석에도 활용할 계획이다.

\section{후 기}

이 연구는 서울과학기술대학교 교내 학술연구비 지원으로 수행 되었습니다.

\section{References}

[1] Armarego, E.J.A, Deshpande, N.P., 1989, Computerized predictive cutting models for forces in end-milling including eccentricity effects, Annals of the CIRP, 38 45-49.

[2] Budak, E., Altintas, Y., Armarego, E.J.A, 1996, Prediction of milling force coefficients from orthogonal cutting data, Transactions of the ASME Journal of Manufacturing Science and Engineering, 118:2 216-224.
[3] Yucesan, G., Altintas, Y., 1994, Improved modeling of cutting force coefficients in peripheral milling, International Journal of Machine Tools and Manufacture, 34 473-487.

[4] Kang, I.S., Kim, J.S., Kim, J.H., Kang, M.C., Seo, Y.W., 2007, A mechanistic model of cutting force in the micro end milling process, Journal of Materials Processing Technology, 187 250-255.

[5] Kline, W.A., DeVor, R.E., 1982, The prediction of cutting forces in end milling with application of cornering cuts, International Journal of Machine Tool Design and Research, 22 7-22.

[6] Sutherland, J.W., DeVor, R.E., 1986, An improved method for cutting force and surface error prediction in flexible end milling system, Transactions of the ASME Journal of Engineering for Industry, 108 269-279.

[7] Afazov, S.M., Ratchev, S.M., Segal, J., 2010, Modelling and simulation of micro-milling cutting forces, Journal of Materials Processing Technology, 210 2154-2162.

[8] Altintas, Y., Spence, A., 1991, End milling force algorithms for CAD systems, Annals of the CIRP, 40 31-34.

[9] Perez, H., Vizan, A., Hernandez, J.C., Guzman, M., 2007, Estimation of cutting forces in micromilling through the determination of specific cutting pressures, Journal of Materials Processing Technology, 190 18-22.

[10] Tlusty J., Macneil, P., 1975, Dynamics of cutting forces in end milling, Annals of the CIRP, 24 21-25.

[11] Bao, W.Y., Tansel, I.N., 2000, Modeling micro-end-milling operations. Part I: analytical cutting force model, International Journal of Machine Tools and Manufacture, 40 2155-2173.

[12] Liu, X.W., Cheng, K., Webb, D., Luo, X.C., 2002, Prediction of cutting force distribution and its influence on dimensional accuracy in peripheral milling, International Journal of Machine Tools and Manufacture, 42:7 791-800. 